\title{
Phylogeny and biogeography of the lucanid beetles of the tribe Aesalini (Insecta, Coleoptera, Lucanidae), with special reference to the effect of Himalayan uplift as the vicariance event
}

\author{
Kunio Araya
}

Graduate School of Social and Cultural Studies, Kyushu University, Ropponmatsu 4-2-1, Chuo-ku, Fukuoka, 810-8560 JAPAN

For correspondence, E-mail:arayarcb@mbox.nc.kyushu-u.ac.jp

The lucanid tribe Aesalini (Insecta, Coleoptera, Lucanidae) consists of the three genera, Aesalus Fabricius, 1801, Lucanobium Howden et Lawrence, 1974 and Echinoaesalus Zelenka, 1993 (Krajcik, 2001). Of these, the genus Aesalus includes more than 10 species from both the Old and NewWorlds, while Lucanobium is containing two species from South America (Araya and Yoshitomi, 2003). The genus Echinoaesalus has most recently been erected based on the Indonesian species, E. jaechiZelenka, 1993, and afterwards, all the Southeast Asian species which had belonged to the genus Aesalus were moved to the genus Echinoaesalus (Araya et al. 1998, Zelenka 1994). In the present study, phylogenetic relationships among 22 species of the tribe Aesalini (including the genera Aesalus, Echinoaesalus and Lucanobium) are analyzed based on the adult morphologies (a total of 36 characters).
The resultant phylogeny demonstrates that the Aesalini is composed of two major lineages, northern Aesalini and southern Aesalini lineages. The northern Aesalini lineage is composed of three major lines: a Palearctic Aesalus line (containing $A$. scarabaeoides from Europe, $A$. ulanoskii from Caucasus and $A$. asiaticus from Japan), African Aesalus line (Aesalus sp. from Zaire) and a Chinese Aesalus line (containing A. imanishii from Taiwan and $A$. sichuanensis from West China). The southern Aesalini lineage contains two major lines: a Himalayan Aesalus and a tropical Aesalini line. The former line consists of $A$. himalayicus complex and the latter consists of two major groups: a bristly tropical Aesalini group (containing A. satoi from Laos, Neotropical Aesalus members and southeast Asian E. matsuii complex) and a clumpy Aesalini group (containing Neotropical Lucanobium and southeast Asian E. timidus- hidakai subgroup).

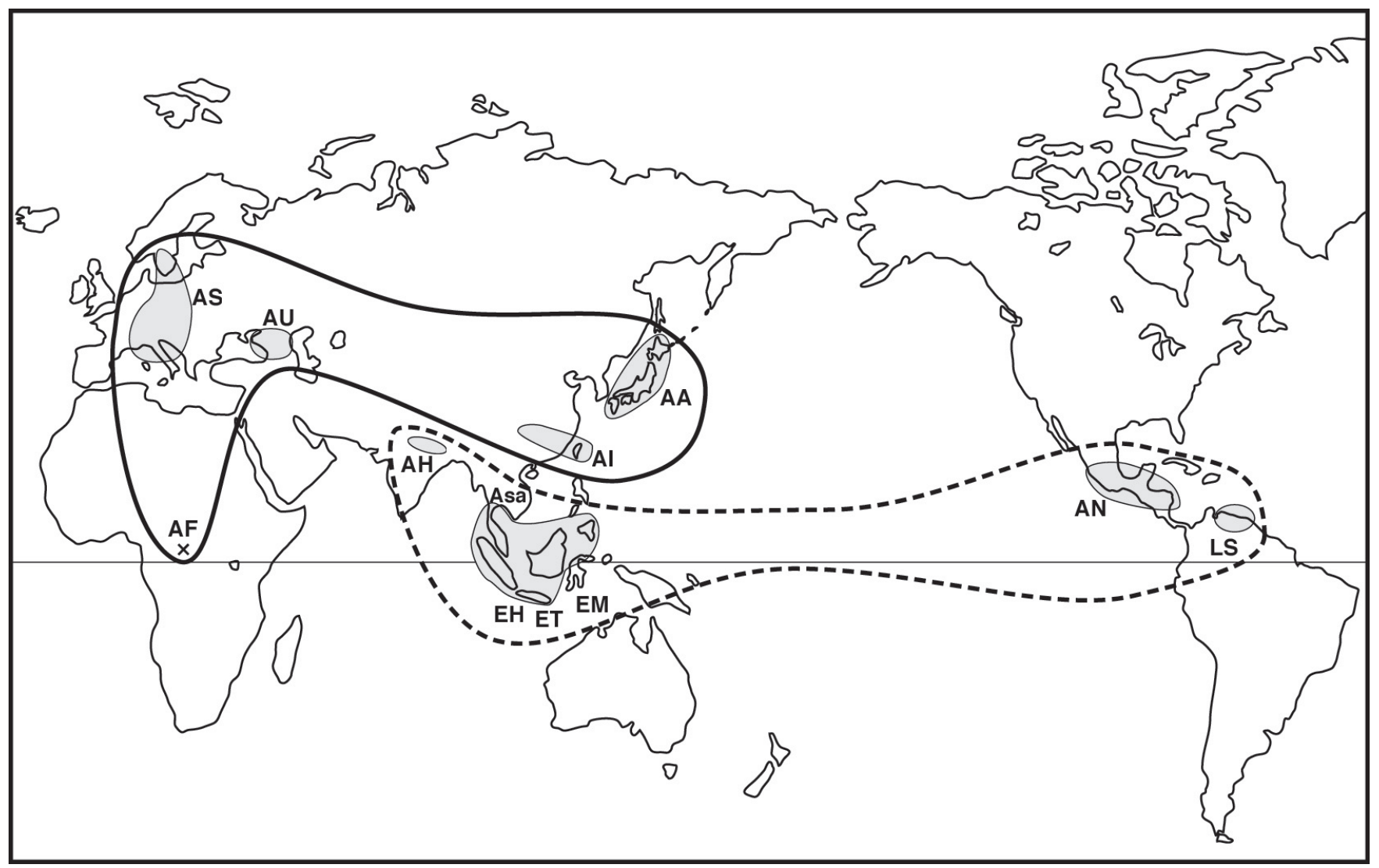

FIGURE 1. Map showing the distribution of the tribe Aesalini. $A S=A$. scarabaeoides, $A U=A$. ulanowskii, $A A=A$. asiaticus, $A H=A$. himalayicus complex, $\mathrm{Al}=\mathrm{A}$. imanishii complex, Asa=A. satoi, AN=A. neotropicalis complex, $\mathrm{LS}=\mathrm{L}$. squamosum complex, $\mathrm{EM}=\mathrm{E}$. $m$ atsuii complex, $\mathrm{ET}=\mathrm{E}$. timidus complex and $\mathrm{EH}=\mathrm{E}$. hidakai complex 
The inferred phylogenetic patterns among the members of Aesalini indicated that the A. himalayicus complex and the $A$. imanishii complex, both of which showed relic distributions in the Asian Continent, retained the most ancestral character states in the northern Aesalini and the southern Aesalini lineages, respectively. Further, recently a fossil genus, Cretaesalus Nikolajev, 1993, belonging to the subfamily Aesalinae was described from the upper Cretaceous stratum of Kazakhstan. Based on these paleontological and neontological information, it is suggested that the ancestor of Aesalini originated in the Eurasian Continent, possibly around the Himalayas, and that Himalayan uplift, the great vicariance event against dispersal and gene flow, may strongly effect on the initial divergence between two major lineages, northern Aesalini and southern Aesalini lineages. In the southern Aesalini lineage, the Himalayan Aesalus line and the tropical Aesalini line were separated in the Oriental Region. In the tropical Aesalini line, the bristly and clumpy Aesalini groups were separated in Southeast Asia. Thereafter, both the ancestor of Lucanobium in the clumpy Aesalini groups and the ancestor of $A$. neotropicalis complex migrated from the Old World to the NewWorld through the Bering Land Bridge like tapirs (Mammalia, Perissodactyla).

\section{References}

Araya K, Yoshitomi H. 2003. Discovery of the lucanid genus Aesalus (Coleoptera) in the Indochina region, with description of a new species. Spec Bull Jpn Soc Coleopterol Tokyo (6): 189-199

Araya K, Tanaka M \& Bartolozzi L. 1998. Taxonomic review of the genus Aesalus (Coleoptera: Lucanidae) in the Himalayas. European J Entomol 95: 407-416

Krajcik M. 2001. Lucanidae of the world, Catalogue Part I. Checklist of the stag beetles of the world (Coleoptera: Lucanidae). Czech, 2001: $108 \mathrm{p}$

Nikolajev GV. 1993. Nahodka grebenchatousogo zhuka (Coleoptera Lucanidae) v verkhnem mele Kazakhstana. Selevinia 1993(1): 89-92

ZelenkaW. 1994. Zwei neue Echinoaesalus-Arten aus Sostasien (Coleoptera, Lucanidae). Z Arbgem Oster Ent 46 (1/2): 56-61 